\title{
BMJ Open Spatiotemporal variations of asthma admission rates and their relationship with environmental factors in Guangxi, China
}

\author{
Rui Ma, ${ }^{1}$ Lizhong Liang, ${ }^{2}$ Yunfeng Kong (D) , ${ }^{1}$ Mingyang Chen, ${ }^{2}$ Shiyan Zhai, ${ }^{1}$ \\ Hongquan Song, ${ }^{1}$ Yane Hou, ${ }^{3}$ Guangli Zhang ${ }^{1}$
}

To cite: Ma R, Liang L, Kong Y, et al. Spatiotemporal variations of asthma admission rates and their relationship with environmental factors in Guangxi, China. BMJ Open 2020;10:e038117. doi:10.1136/ bmjopen-2020-038117

- Prepublication history for this paper is available online To view these files, please visit the journal online (http://dx.doi org/10.1136/bmjopen-2020038117).

Received 28 February 2020 Revised 13 August 2020 Accepted 21 August 2020
Check for updates

(C) Author(s) (or their employer(s)) 2020. Re-use permitted under CC BY-NC. No commercial re-use. See rights and permissions. Published by BMJ.

${ }^{1}$ Key Laboratory of Geospatial Technology for the Middle and Lower Yellow River Regions, Henan University, Kaifeng, China ${ }^{2}$ The Affiliated Hospital, Guangdong Medical University, Zhanjiang, China

${ }^{3}$ College of Computer and Information Engineering, Henan University, Kaifeng, China

Correspondence to Dr Yunfeng Kong; yfkong@henu.edu.cn

\section{ABSTRACT}

Objective The study aimed to determine if and how environmental factors correlated with asthma admission rates in geographically different parts of Guangxi province in China.

Setting Guangxi, China.

Participants This study was done among 7804 asthma patients.

Primary and secondary outcome measures Spearman correlation coefficient was used to estimate correlation between environmental factors and asthma hospitalisation rates in multiple regions. Generalised additive model (GAM) with Poisson regression was used to estimate effects of environmental factors on asthma hospitalisation rates in 14 regions of Guangxi.

Results The strongest effect of carbon monoxide (C0) was found on lag1 in Hechi, and every $10 \mu \mathrm{g} /$ $\mathrm{m}^{3}$ increase of $\mathrm{CO}$ caused an increase of $25.6 \%$ in asthma hospitalisation rate (RR $1.26,95 \% \mathrm{Cl} 1.02$ to 1.55). According to the correlation analysis, asthma hospitalisations were related to the daily temperature, daily range of temperature, $\mathrm{CO}$, nitrogen dioxide $\left(\mathrm{NO}_{2}\right)$ and particulate matter $\left(\mathrm{PM}_{2.5}\right)$ in multiple regions. According to the result of GAM, the adjusted $\mathrm{R}^{2}$ was high in Beihai and Nanning, with values of 0.29 and 0.21 , which means that environmental factors are powerful in explaining changes of asthma hospitalisation rates in Beihai and Nanning. Conclusion Asthma hospitalisation rate was significantly and more strongly associated with $\mathrm{CO}$ than with $\mathrm{NO}_{2}$, $\mathrm{SO}_{2}$ or $\mathrm{PM}_{25}$ in Guangxi. The risk factors of asthma exacerbations were not consistent in different regions, indicating that targeted measures should differ between regions.

\section{INTRODUCTION}

Asthma is a common chronic inflammatory respiratory disease. Among susceptible individuals, asthma can cause wheezing, dyspnoea, chest tightness and coughing, especially at night or early in the morning. ${ }^{1}$ It seriously threatens public health. In 2004, approximately 300 million people suffered from asthma worldwide ${ }^{2}$; in 2008, about 30 million people suffered from asthma
Strengths and limitations of this study

- The study area covered 14 regions in Guangxi, with an area of $237600 \mathrm{~km}^{2}$ and a population of 48 million people.

- We analysed temporal and spatial variations of asthma hospitalisation rates for 14 regions.

- Spearman correlation coefficient was used to perform correlation analysis between meteorological factors, air pollutants and asthma hospitalisation rates in 14 regions.

- Generalised additive modelGeneralised additive model was used to explore the associations between air pollutants, meteorological factors and asthma in 14 regions, respectively.

- This study did not consider the effect of biological air pollutants on asthma due to the lack of data.

in China; both figures have been steadily increasing. ${ }^{4}{ }^{5}$ The risk factors for asthma include genetics, gender and the environment, while environmental risk factors include meteorological conditions, allergens in the air, viral respiratory infections, smoke, air pollution, occupation and diet. ${ }^{6-8}$

Air pollutants and meteorological factors related to asthma have been reported worldwide. ${ }^{9-26}$ Some studies found that climatic differences had a significant influence on asthma. ${ }^{19-23}$ Several prior studies have shown that temperature influences asthma exacerbations. ${ }^{1120-23}$ Some studies showed evidence of an association between air pollutants and asthma. ${ }^{14-1924}$ Tian et al found a significant association between particulate matter $\left(\mathrm{PM}_{2.5}\right)$ and daily exacerbations of asthma. ${ }^{9}$ Nitrogen dioxide $\left(\mathrm{NO}_{2}\right)$ and carbon monoxide $(\mathrm{CO})$ were found to have the greatest impact on asthma. ${ }^{11} 15$ Numerous studies have been done on the associations between air pollutants, meteorological factors and asthma, but the conclusions are inconsistent. ${ }^{101113142126}$ 
The relationship between asthma and environmental factors varies from region to region, and spatial difference in asthma should be taken into account. ${ }^{23}{ }^{25}$ The prevalence of asthma may vary with location, ${ }^{27}$ and changes in environmental factors in different seasons greatly influence respiratory diseases. ${ }^{28}$ For instance, the correlation between asthma and $\mathrm{O}_{3}$ varies with seasons, and there are regional differences in sulfur dioxide $\left(\mathrm{SO}_{2}\right)$ levels. ${ }^{29}$ The associations between air pollutant concentrations and asthma hospitalisation differ from region to region, ${ }^{30}$ and most studies have only assessed the effects of environmental factors on asthma hospitalisation in single region. Chang et al considered the influence of geographical factors on asthma and analysed the relationship between food, dog ownership, housing area and disposable income from the perspective of community variables and found that asthma incidence differed by region, ${ }^{31}$ but did not consider the effects of meteorological factors and air pollution on asthma. There are significant regional changes in some environmental factors that affect asthma, but these are often ignored. It is necessary to explore the relationship between environmental factors of asthma hospitalisation in multiple regions. In addition, there were lots of studies exploring association between air pollution and asthma in China. However, to our knowledge, regions of studies were often concentrated on areas with high level of air pollution in the north and central China, such as Beijing, Shanghai, Jinan and Hefei. ${ }^{9} 11182032$ Considering geographical disparities and air pollution characteristics, it is essential to explore the impacts of air pollution on asthma in areas with low level of air pollution in southern China.

Guangxi is located in southern China with low level of air pollution. The prevalence of asthma has been reported to be at a moderate level in Guangxi, China. ${ }^{32}{ }^{33}$ In this study, we used the 14 regions (cities) in Guangxi as a study area; these regions include both coastal and inland areas with different geographical and climatic characteristics. This study attempted to explore the spatiotemporal patterns of asthma hospitalisations and its relationship with environmental factors in 14 regions in Guangxi. The conclusions may be useful for public health departments to provide targeted preventive measures.

\section{METHODS}

\section{Study design}

In this study, daily data were used to explore the relationship between air pollutants, meteorological factors and asthma hospitalisation rates in 2015. First, Spearman correlation coefficient was applied to evaluate the correlations between meteorological factors, air pollutants and asthma hospitalisation rates in 14 regions, respectively. Second, we combined generalised additive model (GAM) with Poisson regression to quantify the degree of interaction between environmental factors responsible for the variation in asthma hospitalisation rate. Finally, we estimated the relative risk (RR) between exposure to air pollutants and hospitalisation for asthma and explored the lagging effects of environmental factors on asthma.

\section{Research location and data source}

This study was performed in 14 regions in Guangxi (figure 1), China, with an area of $237600 \mathrm{~km}^{2}$. Guangxi has a subtropical monsoon climate. ${ }^{34}$ Geographically, the land slopes from northwest to southeast. The topography and related climatic characteristics vary greatly in different regions of Guangxi. The air pollution in Guangxi is mainly

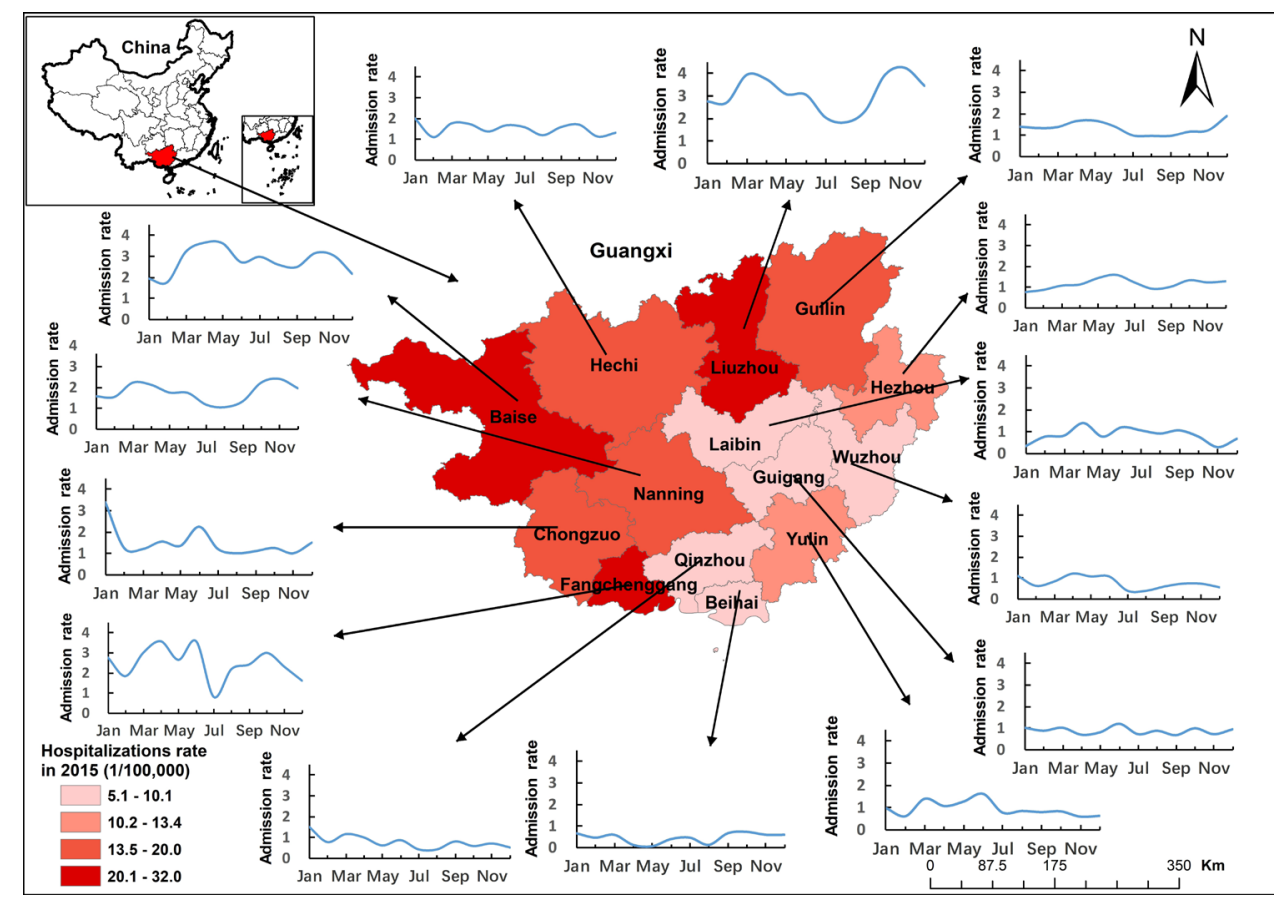

Figure 1 Geographic location of Guangxi in China, and asthma hospitalisations in 14 regions in Guangxi (2015). 
generated locally, and not blown in from other areas. ${ }^{35}$ Guangxi has four seasons: spring (March-May), summer (June-August), autumn (September-November) and winter (December-February).

Daily hospitalisation cases for asthma were originally collected from all county-level and city-level hospitals in 14 regions in Guangxi, China. None of the asthma data we obtained contained personal information. We have obtained ethics approval for our study, and this study was approved by the biomedical research ethical subcommittee of Henan University (China). These hospitals were almost evenly distributed in 14 regions of Guangxi, with each region containing at least two hospitals. Asthma data were collected from hospital records dated 1 January-31 December 2015, based on the disease codes defined by the 10th Revision of the International Classification of Diseases. Diagnostic coding of 'J45.xxx', such as 'J45.900', 'J45.901' and 'J45.902', returned 7804 hospital admissions in 2015 due to asthma. The contents of records were diagnostic information, admission date, duration of hospital stay, age, sex and residence address. In this study, we aggregated the asthma cases at the city level according to the patient's residence address. Patients with residence address outside Guangxi were excluded.

Daily data of environmental factors were collected, including air pollution concentration, and meteorological data from 1 January to 31 December 2015. Daily air pollutant data aggregated data for the 14 regions, directly collected from China's air quality online platform of monitoring and analysis (https://www.aqistudy.cn/historydata). The data included: average daily level of $\mathrm{SO}_{2}, \mathrm{NO}_{2}, \mathrm{PM}_{2.5}$ and CO. Daily meteorological factors were obtained from 600 monitoring stations as found on the National Meteorological Information Center website (http://data.cma.cn/), including daily average temperature $(\mathrm{T})$, daily maximum temperature, daily minimum temperature, average relative humidity percentage (RHU) and average wind speed (WIN). Daily meteorological factors for the 14 regions were interpolated from data based on 600 monitoring sites in China. Moreover, this study introduced daily range of temperature (TDIFF), referring to the difference between the maximum and minimum temperatures on the same day, as an influencing factor. Demographic characteristics for the 14 regions were obtained from 2015 Guangxi Statistical Yearbook ${ }^{36}$ and the Sixth National Census in 2010. ${ }^{37}$ The populations of the 14 regions in 2015 were available from the Guangxi Statistical Yearbook; populations of specific age groups were modelled weights based on the Sixth National Census in 2010. ${ }^{37}$

\section{Patient and public involvement}

Patients and the public were not involved in the design or planning of the study.

\section{Analysis model}

In this study, Spearman correlation coefficient was used to study the correlation of air pollutant, and meteorological factors with daily hospital admission rates due to asthma for 14 regions in 2015, respectively. In this study, we used two-sided test, and $p$ values smaller than 0.05 were considered statistically significant. Spearman correlation coefficient was performed in IBM SPSS Statistics (V.21).

We analysed the effect of the interaction between meteorological factors and air pollutants on asthma, using Poisson regression in a GAM. ${ }^{38} 39$ The relationship between explanatory variables and dependent variables was established by using smoothing function, which is linear or non-linear. ${ }^{40}$ A non-parametric GAM was established to quantify the effect of the interaction between environmental factors on asthma hospitalisation. To explore the effects of long-term trends and weeks on the results, we introduced week variables and date sequence variables. The model is described as follows:

$$
\begin{aligned}
\log (\text { E }[\text { Admissions }]) & =\mathrm{s}(\mathrm{T})+\mathrm{s}(\mathrm{TDIFF})+\mathrm{s}(\mathrm{RHCU})+\mathrm{s}(\mathrm{WIN}) \\
& +\mathrm{s}(\mathrm{PM} 2.5)+\mathrm{s}(\mathrm{SO} 2)+\mathrm{s}(\mathrm{CO}) \\
& +\mathrm{s}(\mathrm{NO} 2)+\mathrm{te}(\mathrm{DOY})+\mathrm{te}(\mathrm{DOW})
\end{aligned}
$$

where $\mathrm{Y}$ represents daily asthma hospitalisation rate, and T, TDIFF, RHU, WIN, $\mathrm{PM}_{2.5}, \mathrm{SO}_{2}, \mathrm{CO}$ and $\mathrm{NO}_{2}$ were explanatory variables. $\mathrm{T}$ is the daily average temperature; TDIFF is the daily range of temperature; RHU is the average relative humidity percentage and WIN is the average wind speed. DOY is the day of the year, and DOW is the day of the week. $s($.$) is the thin plate regression spline smooth$ function and te(.) is the tensor product smooth function. The outcome variables were adjusted $\mathrm{R}^{2}$ and deviance explained. Adjusted $\mathrm{R}^{2}$ measures the degree to which the response variable is related to all explanatory variables. In GAM, the 'deviance' is similar to likelihood-ratio statistic, which is widely used in generalised linear models. Here, the variable deviance explained the ability of explanatory variables to explain the variation in hospitalisation rates.

Then, a semiparametric GAM with Poisson link was used to estimate the exposure-response relationships between air pollutants and asthma while adjusting for confounding variables, including week effect and meteorological factors. The effects of exposure to meteorological factors and air pollutants may lead to asthma hospitalisation on the same day or later. In this study, we performed GAMs both on the same day with hospitalisation ( $\operatorname{lag} 0$ ) and on the 5 following days (lag 1 to lag 5 ). The model is described as follows:

$$
\begin{aligned}
\log (\mathrm{E}[\mathrm{Y}])= & \beta \mathrm{Xi}+\mathrm{s}(\mathrm{T})+\mathrm{s}(\mathrm{TDIFF})+\mathrm{s}(\mathrm{RHU}) \\
& +\mathrm{s}(\mathrm{WIN})+\mathrm{te}(\mathrm{DOY})+\mathrm{te}(\text { DOW })
\end{aligned}
$$

where $\mathrm{Y}$ is the daily number of asthma admissions, and $\mathrm{X}_{\mathrm{i}}$ are the daily concentrations of $\mathrm{CO}, \mathrm{NO}_{2}, \mathrm{SO}_{2}$ and $\mathrm{PM}_{2.5}$, respectively. $\beta$ is the coefficient of $\mathrm{X}_{\mathrm{i}}$ in the model. The estimated effects were RR with $95 \% \mathrm{CI}$, corresponding to an increment of $10 \mu \mathrm{g} / \mathrm{m}^{3}$ in the levels of $\mathrm{CO}, \mathrm{NO}_{2}, \mathrm{SO}_{2}$ and $\mathrm{PM}_{2.5}$.

$R R$ was calculated by the following equation:

$R R=e^{\beta \times k},(3)$ where $k$ is the unit of increase for $X_{i}$, and CI is $(\exp [(\beta-1.96 \times \mathrm{Se}) \times \mathrm{k}], \exp [(\beta+1.96 \times \mathrm{Se}) \times k])$. Se is the $\mathrm{SE}$ of the model in $\mathrm{Eq}$ (2). 
Table 1 Statistics for air pollutants and meteorological factors for 14 regions in Guangxi in 2015

\begin{tabular}{|c|c|c|c|c|c|c|c|c|}
\hline & $\mathbf{T}$ & TDIFF & RHU & WIN & $\mathrm{PM}_{2.5}$ & $\mathrm{SO}_{2}$ & CO & $\mathrm{NO}_{2}$ \\
\hline Regions & Mean+SD & Mean+SD & Mean+SD & Mean+SD & Mean+SD & Mean+SD & Mean+SD & Mean+SD \\
\hline Baise & & & & & & & & \\
\hline Beihai & & $70+3.74$ & $0.93+23.52$ & & $29.45+5.93$ & $9.05+2.44$ & & \\
\hline Chongzuo & $24.53+0.19$ & $7.32+7.07$ & $4.85+28.40$ & $1.23+8.13$ & $38.23+6.41$ & $10.30+3.11$ & $0.88+0.37$ & $17.65+9.66$ \\
\hline Fangchenggang & $24.96+0.30$ & $6.57+3.19$ & $7.80+21.55$ & $2.01+5.81$ & $30.75+6.33$ & $5.74+2.55$ & $0.82+0.69$ & $12.19+11.42$ \\
\hline Guige & & & & & & $21.73+3.12$ & & \\
\hline Guilin & $20.88+0.33$ & $6.57+10.63$ & $76.52+32.25$ & $1.81+11.10$ & $49.06+7.62$ & $20.41+3.25$ & $1.06+0.79$ & $24.01+$ \\
\hline Hechi & $21.87+0.40$ & $7.09+19.53$ & $82.22+25.49$ & $1.51+9.19$ & $43.92+6.76$ & $23.16+3.37$ & $1.30+0.58$ & $20.77+$ \\
\hline Hezh & $21.22+0.49$ & $7.83+7.19$ & $82.07+26.81$ & & $39.92+7.46$ & $16.11+3$ & & \\
\hline Laibin & $23.18+0.30$ & $7.07+16.34$ & $75.91+29.68$ & $1.27+12.78$ & $43.17+7.19$ & $20.81+3.07$ & $1.00+0$ & $23.96+1$ \\
\hline Liuzhou & $22.58+0.28$ & $6.77+10.92$ & $76.23+32.80$ & $1.44+10.7$ & $49.10+7.36$ & $24.20+3.00$ & $1.08+0.65$ & $23.43+11.1$ \\
\hline Nanning & $23.27+0.22$ & $8.10+4.87$ & $83.12+27.57$ & $1.55+13.25$ & $40.96+6.51$ & $12.67+3.70$ & $0.94+0.62$ & $31.94+7.90$ \\
\hline Qinzhou & $23.81+0.44$ & $7.63+8.03$ & $83.19+25.20$ & $2.06+7.68$ & $35.91+6.50$ & $17.21+3.36$ & $1.24+0.81$ & $19.38+8.42$ \\
\hline Wuzhou & $22.98+0.74$ & $8.27+6.62$ & $81.11+21.30$ & $1.96+9.09$ & $35.82+6.72$ & $16.66+3.10$ & $1.23+0.56$ & $21.16+9.75$ \\
\hline Yulin & $23.80+0.45$ & $7.43+25.44$ & $84.51+27.02$ & $2.25+8.68$ & $39.17+6.25$ & $27.94+2.90$ & $1.20+0.97$ & $21.16+10.31$ \\
\hline
\end{tabular}

$\mathrm{CO}$, carbon monoxide $\left(\mathrm{mg} / \mathrm{m}^{3}\right) ; \mathrm{NO}_{2}$, nitrogen dioxide $\left(\mu \mathrm{g} / \mathrm{m}^{3}\right) ; \mathrm{PM}_{2.5}$, particulate matter $\left(\mu \mathrm{g} / \mathrm{m}^{3}\right) ; \mathrm{RHU}$, average relative humidity percentage (\%); $\mathrm{SO}_{2}$, sulfur dioxide $\left(\mu \mathrm{g} / \mathrm{m}^{3}\right)$; T, daily average temperature $\left({ }^{\circ} \mathrm{C}\right)$; TDIFF, daily range of temperature $\left({ }^{\circ} \mathrm{C}\right)$; WIN, average wind speed $(\mathrm{m} / \mathrm{s})$.

We checked the robustness of models to: (1) determine the smoothing parameters and (2) df selection. Tests were conducted with different $\mathrm{df}$ for each variable. In GAM, df in this model were selected by the lowest Akaike information criterion. This study used Generalized cross validation criteria (GCV) as the estimation method to select smoothing parameters.

\section{RESULTS}

\section{General descriptive statistics}

According to the statistics, the ratios of males and females admitted for asthma were $52.1 \%$ and $47.9 \%$, respectively. The patients were grouped by age, with $25.9 \%$ of patients $0-14$ years old, $4.7 \%$ of patients $15-29$ years old, $11.6 \%$ of patients $30-44$ years old, $22.4 \%$ of patients $45-59$ years old, $23.4 \%$ of patients $60-75$ years old and $12.0 \%$ of patients over 75 years old. Table 1 shows the daily average environmental factors for 14 regions in Guangxi in 2015. The annual average temperature in Guangxi was between $20.9^{\circ} \mathrm{C}$ and $25.2^{\circ} \mathrm{C}$, with the temperature in the south higher than in the north. The range of daily temperature was largest in Baise. The average daily WIN was higher in coastal regions. In several regions, $\mathrm{PM}_{2.5}$ concentration was higher than the Chinese national standard $(35 \mu \mathrm{g} /$ $\mathrm{m}^{3}$ ) for ambient air quality. ${ }^{41}$ The concentrations of $\mathrm{CO}, \mathrm{NO}_{2}$ and $\mathrm{SO}_{2}$ in all 14 regions were lower than the Chinese national standard for ambient air quality. ${ }^{41}$

Figure 1 shows the time trends of asthma hospitalisation rates adjusted for different regions. The peak asthma hospitalisation rates occurred in March-May and September-November, with troughs in February, July and August (figure 1). Baise, Liuzhou, Nanning and Wuzhou had peaks in spring and autumn, while in Guilin, asthma admission rates peaked in spring and winter. The hospital admission rates in Baise, Hechi, Liuzhou and Fangchenggang were relatively high compared with other regions. The admission rates in Qinzhou, Yulin and Beihai were low and their trends were similar. Spatial heterogeneity was found in the distribution of asthma hospital admissions. Figure 2 shows the time distribution of asthma hospital admissions by age groups. The time trends of asthma in different age groups were not consistent in different regions. The number of asthma hospitalisations was highest in the $0-14$ age group.

\section{Air pollutants and meteorological factors impact on asthma Correlation analysis}

The correlation between air pollutants, meteorological factors and asthma admission rates in 14 regions in Guangxi, according to the result of Spearman, is shown in figure 3. As shown, not all correlations were statistically significant. T, TDIFF, $\mathrm{CO}$ and $\mathrm{NO}_{2}$ were correlated with asthma admission rates in multiple regions. $\mathrm{T}$ was positively correlated with asthma in Baise, Laibin and Yulin, and $\mathrm{T}$ was negatively correlated with asthma in Liuzhou, Nanning, Qinzhou and Beihai. Asthma was positively correlated with TDIFF in four regions. $\mathrm{CO}$ was positively correlated with asthma in four regions, and negatively correlated with asthma in two regions. Relationship between $\mathrm{CO}$ and asthma was more pronounced in central Guangxi. $\mathrm{NO}_{2}$ was related to asthma admission rate in regions of eastern Guangxi. $\mathrm{PM}_{2.5}$ had strongly positive correlation with asthma hospitalisation in Hechi, Qinzhou and Beihai. $\mathrm{SO}_{2}$ was positively correlated with asthma admission rate only in Beihai. Average WIN was only found to correlate with the asthma admission rate in 

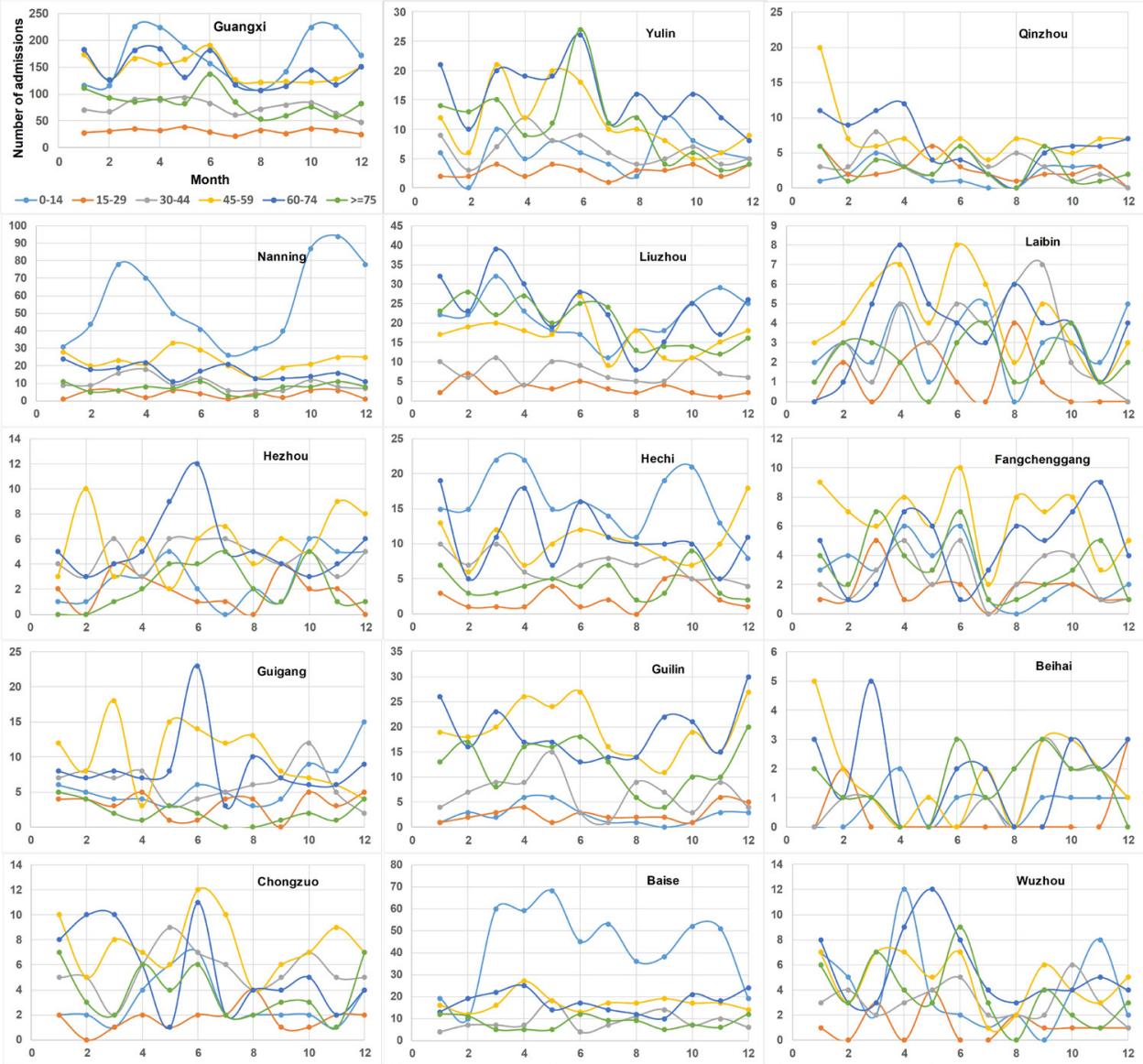

Figure 2 Time distribution of asthma hospital admissions by age groups in 2015 .

Yulin. There did not appear to be any correlation between the asthma admission rate and environmental factors in Chongzuo or Hezhou.

\section{Interaction analysis}

The fitting effects between air pollutants, meteorological factors and the asthma hospitalisation rates in Guangxi are shown in table 2 , and the results are all statistically significant. In 2015, the fitting effects of multiple factors on asthma hospitalisation rates were good in Beihai, Naning, Laibin and Liuzhou, with adjusted $\mathrm{R}^{2}$ values of $0.29,0.21$, 0.19 and 0.18 , respectively, which meant that environmental factors were powerful in explaining changes in asthma hospitalisation rates in Beihai, Naning, Laibin and Liuzhou. The value of deviance explained was $40.5 \%$ in Beihai, which indicated that the interaction between air pollutants and meteorological factors explained $40.5 \%$ of the variation of asthma hospitalisation in Beihai. The combined effects of environmental factors on asthma were low in Chongzuo and Hezhou. The fitting effects between meteorological factors, air pollutant concentrations and asthma hospitalisation rates are shown in figure 4 . There were non-linear relationships between all risk factors and asthma hospitalisation rates, and the relationships differed from region to region. Although the overall relationship between environmental factors and hospitalisation rates was non-linear, some factors showed a linear relationship in certain intervals. When $\mathrm{PM}_{25}$ concentration was high, $\mathrm{PM}_{25}$ concentration was associated with increased risks of hospitalisation in Guilin, Liuzhou, Guigang, Yulin, Hezhou and Laibin (figure 4). When $\mathrm{NO}_{2}$ concentration exceeded $70 \mu \mathrm{g} / \mathrm{m}^{3}$, the hospitalisation rate of asthma was positively correlated with $\mathrm{NO}_{2}$ in Nanning, Guilin, Liuzhou and Guigang (figure 4).

The fitting effects between multiple environmental factors and asthma admission rates, adjusted for age, are shown in table 3 . The value of deviance explained for $0-14$ age group was $37.2 \%$, which indicated that the interaction between air pollutants and meteorological factors explained $37.2 \%$ of the variation of asthma hospitalisation. The deviance explained for the 60-74 age group was second only to $0-14$ age group, with a value of $25.9 \%$. The fitting effects between multiple environmental factors and asthma were relatively low for the 15-29, 30-44 and 45-59 age groups, with $\mathrm{R}^{2}$ values of $0.12,0.15$ and 0.14 . Residents aged $0-14$ with asthma may be more affected by environmental factors than other age groups.

\section{Air pollutant exposure assessment}

Table 4 shows the statistically significant percentage increases of asthma hospitalisation rate for different regions with $10 \mu \mathrm{g} / \mathrm{m}^{3}$ increases in $\mathrm{CO}, \mathrm{PM}_{25}, \mathrm{SO}_{2}$ and $\mathrm{NO}_{2}$ concentrations. In Hechi, $\mathrm{CO}$ had a notable effect on asthma hospitalisation from lag0 to lag5. The strongest effect of $\mathrm{CO}$ was 


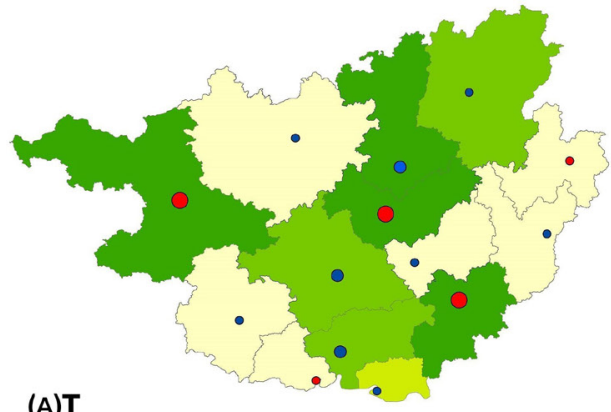

(A)T
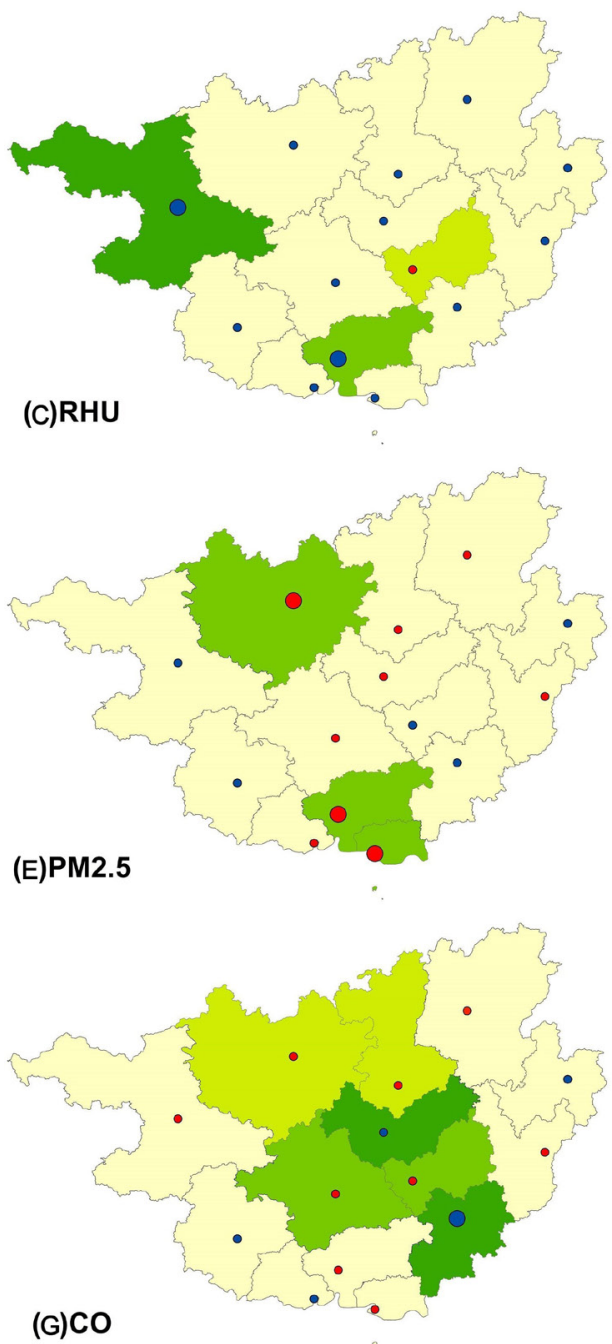

(B)Tdiff
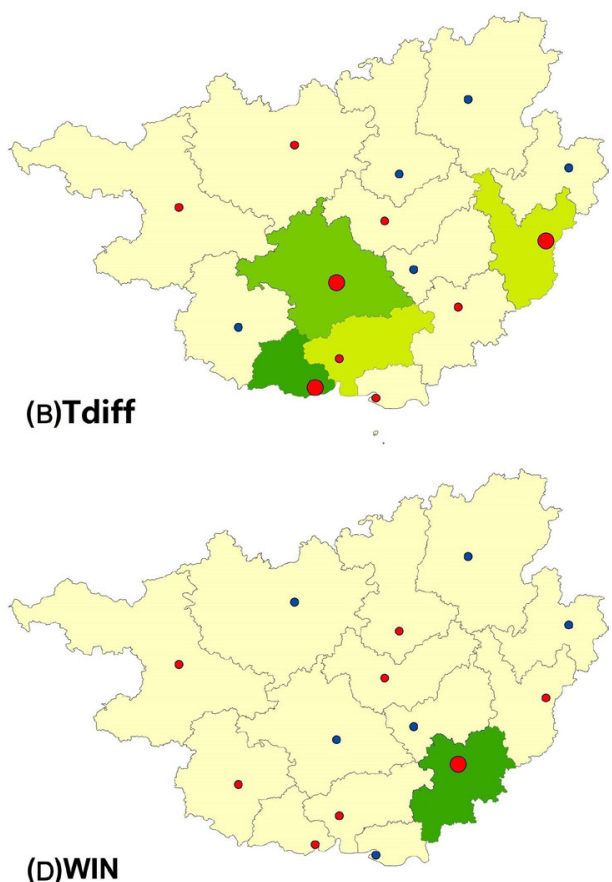

(D)WIN
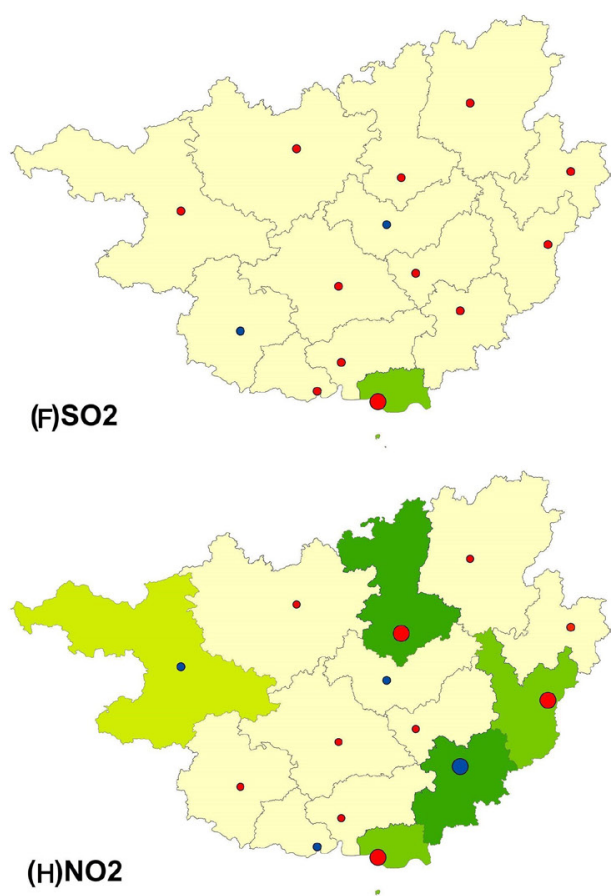

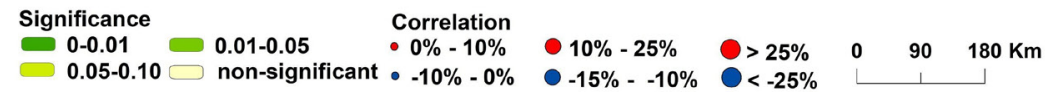

Figure 3 Correlation analysis between environmental factors and asthma hospitalisation rates in Guangxi (2015). Environmental factors are (A) T: daily average temperature, (B) Tdiff: daily range of temperature, (C) RHU: daily average relative humidity percentage, (D) WIN: daily average wind speed, $(E) \mathrm{PM}_{25}$ : fine particles 2.5 microns or less in diameter, (F) $\mathrm{SO}_{2}$ : sulfur dioxide, (G) CO: carbon monoxide, $(\mathrm{H}) \mathrm{NO}_{2}$ : nitrogen dioxide.

found on lag1 in Hechi, and every $10 \mu \mathrm{g} / \mathrm{m}^{3}$ increase of CO caused an increase of $25.6 \%$ in asthma hospitalisation rate (RR $1.26,95 \% \mathrm{CI} 1.02$ to 1.55 ). In Baise, the statistically significant effects of $\mathrm{CO}$ were found on lag2-lag4 and of $\mathrm{SO}_{2}$ were only found on lag2.

\section{DISCUSSION}

This study showed that there were seasonal and regional differences for asthma admission rates in the 14 regions in Guangxi. We found evidence of spatial heterogeneity in asthma admission rates and their relationship with 
Table 2 Interaction between air pollutants and meteorological factors on asthma hospitalisations in 14 regions in Guangxi (2015)

\begin{tabular}{llllll}
\hline Regions & $\mathbf{R}^{\mathbf{2}}$ (adj) & Deviance explained (\%) & Regions & $\mathbf{R}^{\mathbf{2}}$ (adj) & Deviance explained (\%) \\
\hline Baise & 0.13 & 29.5 & Hezhou & 0.03 & 20.4 \\
Beihai & 0.29 & 40.5 & Laibin & 0.19 & 26.1 \\
Nanning & 0.21 & 34.3 & Liuzhou & 0.18 & 31.8 \\
Fangchenggang & 0.06 & 21.2 & Chongzuo & 0.03 & 17.7 \\
Guigang & 0.10 & 23.4 & Qinzhou & 0.16 & 26.2 \\
Guilin & 0.12 & 27.0 & Wuzhou & 0.16 & 25.6 \\
Hechi & 0.08 & 21.1 & Yulin & 0.12 & 26.0 \\
\hline
\end{tabular}

All results are significant at $p<0.01$

environmental factors. The hospital admission rates of asthma in the northwest and west of Guangxi were higher than those in the east and south. The correlation between air pollutants, meteorological factors and asthma admission rates also differed in the 14 regions. In our study, although the overall relationships between environmental

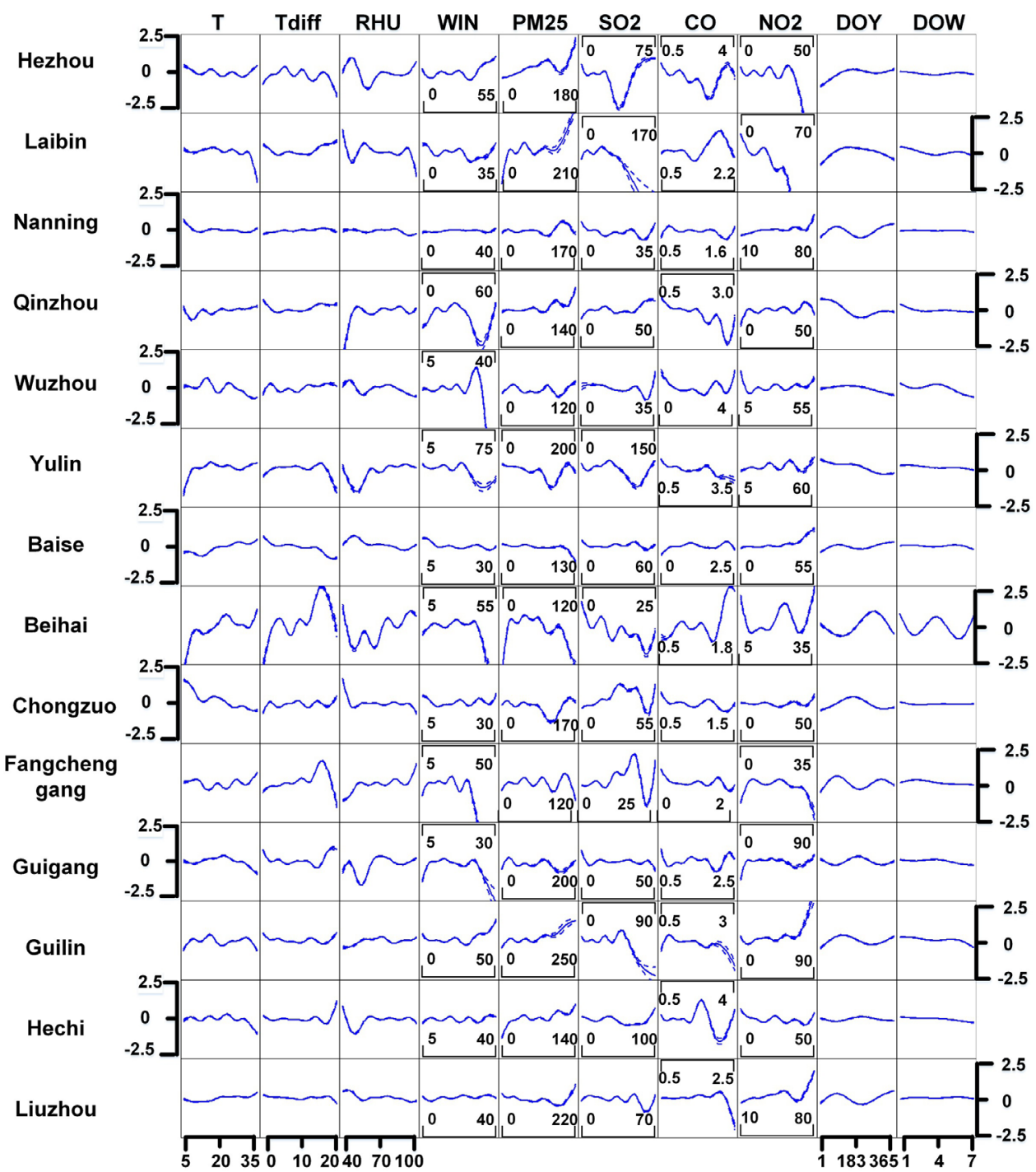

Figure 4 Generalised additive model for the relationships between air pollutants, meteorological factors and asthma hospitalisation rates in 14 regions (2015). $\mathrm{CO}$, carbon monoxide; DOW, day of the week; DOY, day of the year; $\mathrm{NO}_{2}$, nitrogen dioxide; $\mathrm{PM}_{2.5}$, fine particles 2.5 microns or less in diameter; $\mathrm{RHU}$, average relative humidity percentage; $\mathrm{SO}_{2}$, sulfur dioxide; $\mathrm{T}$, daily average temperature; TDIFF, daily range of temperature; WIN, average wind speed. 
Table 3 Interaction between air pollutants and meteorological factors on asthma hospitalisations for different age groups in 2015

\begin{tabular}{lll}
\hline Age groups & $\mathbf{R}^{\mathbf{2}}$ (adj) & Deviance explained $(\%)$ \\
\hline $0-14$ & 0.33 & 37.2 \\
$15-29$ & 0.12 & 16.9 \\
$30-44$ & 0.15 & 22.4 \\
$45-59$ & 0.14 & 23.2 \\
$60-74$ & 0.19 & 25.9 \\
$\geq 75$ & 0.16 & 21.5 \\
\hline
\end{tabular}

All results are significant at $p<0.01$

factors and hospitalisation rates were non-linear, some factors showed linear relationships in certain intervals. We also found that residents between $0-14$ years were particularly susceptible to air pollutants and meteorological factors, which was consistent with previous studies. ${ }^{42} 43$

There were seasonal characteristics for asthma hospitalisation rates. In the 14 regions, there were often two peaks of hospital admissions in 1 year, with the peak hospitalisation rates occurring in spring (March-May) and autumn (September-November), and being typically highest in spring. This is similar to the findings of other domestic and foreign studies. Dust mites and allergens are important factors in the induction of respiratory diseases such as asthma. ${ }^{45}$ More pollen and a suitable temperature for dust mites might be the risk factors of high prevalence of asthma in spring. Based on the result of GAM, it was found that the sensitivity of residents between 0 and 14 years old and over 60 years old to environmental factors was stronger than that of residents 15-59 years old. The age group of $0-14$ years old was most sensitive to environmental factors, which might due to the incomplete development of physiological structures and imperfect immune system in patients under $14 .{ }^{16}$ The sensitivity

\begin{tabular}{|c|c|c|c|c|}
\hline Variables & Region & Lags & RR (95\% Cl) & $P$ value \\
\hline $\mathrm{CO}$ & Baise & lag2 & 1.18 (1.03 to 1.35 ) & $<0.05$ \\
\hline $\mathrm{CO}$ & Baise & lag3 & 1.17 (1.02 to 1.35$)$ & $<0.05$ \\
\hline $\mathrm{CO}$ & Baise & lag4 & 1.19 (1.04 to 1.37$)$ & $<0.05$ \\
\hline $\mathrm{CO}$ & Hechi & lag0 & 1.25 (1.02 to 1.54$)$ & $<0.05$ \\
\hline $\mathrm{CO}$ & Hechi & lag1 & 1.26 (1.02 to 1.55$)$ & $<0.05$ \\
\hline $\mathrm{CO}$ & Hechi & lag2 & 1.25 (1.02 to 1.54$)$ & $<0.05$ \\
\hline $\mathrm{CO}$ & Hechi & lag3 & 1.26 (1.02 to 1.55$)$ & $<0.05$ \\
\hline $\mathrm{CO}$ & Hechi & lag4 & 1.27 (1.03 to 1.57$)$ & $<0.05$ \\
\hline $\mathrm{CO}$ & Hechi & lag5 & 1.25 (1.01 to 1.54$)$ & $<0.05$ \\
\hline $\mathrm{SO}_{2}$ & Baise & lag2 & 1.10 (1.00 to 1.20$)$ & $<0.05$ \\
\hline
\end{tabular}

$\mathrm{CO}$, carbon monoxide; $\mathrm{SO}_{2}$, sulfur dioxide. of patients over 60 years old to environmental factors was also relatively higher than other age groups, which has been shown in other studies, and this may be attributed to an overall decline of physiological function. ${ }^{16} 17$

According to the correlation analysis, the dominant environmental factors that affected asthma admissions were not consistent for the 14 regions. Among the meteorological factors, temperature and daily range of temperature were highly correlated with asthma, and the daily range of temperature was positively correlated with asthma in Nanning, Qinzhou, Chongzuo and Wuzhou. Among the air pollutants, $\mathrm{PM}_{2.5}, \mathrm{NO}_{2}$ and $\mathrm{CO}$ were positively correlated with asthma in multiple regions. To our knowledge, there is no consensus among various studies on the air pollutants that affect the onset of asthma. ${ }^{11} 151846-50$ However, we found some similarities in the correlation between air pollutants and asthma across different regions. In our study, $\mathrm{CO}$ was positively correlated with asthma in Guigang, Hechi, Liuzhou and Nanning. In these four regions, the daily average WIN was below $1.60 \mathrm{~m} / \mathrm{s}$ and the daily average $\mathrm{PM}_{25}$ concentration was higher than $40 \mu \mathrm{g} / \mathrm{m}^{3}$. In Guigang, Hechi and Liuzhou, the daily average concentrations of $\mathrm{CO}$, $\mathrm{SO}_{2}$ and $\mathrm{NO}_{2}$ were high. In addition, $\mathrm{PM}_{25}$ was positively correlated with asthma in Hechi and Guigang. There were some similarities in the environmental factors for Hechi and Guigang. For both Hechi and Guigang, the daily average $\mathrm{PM}_{2.5}$ concentration was higher than $40 \mu \mathrm{g}$ / $\mathrm{m}^{3}$, the daily average WIN was low and the daily average RHU was higher than $82 \%$. Possible reasons for these findings were that specific meteorological conditions modified the effect of air pollutants on asthma hospitalisations. ${ }^{12} 13$ The effect of the interaction between meteorological factors and air pollution on asthma deserves further study. Uniform policy interventions may not work uniformly due to regional difference in environmental factors $^{48}$; it is essential for governments or regulatory agencies to formulate different prevention policies for different regions, according to specific environmental, geographical and meteorological conditions.

In our study, although the overall relationships between environmental factors and hospitalisation rates were non-linear, some factors showed linear relationships in certain intervals. When $\mathrm{PM}_{2.5}$ concentration was high, $\mathrm{PM}_{2.5}$ concentration was positively correlated with asthma in multiple regions. In Nanning, Guilin, Liuzhou and Guigang, the hospitalisation rates were positively correlated with $\mathrm{NO}_{2}$ when $\mathrm{NO}_{2}$ concentration exceeded $70 \mu \mathrm{g} / \mathrm{m}^{3}$. Research on the relationship between asthma and temperature has shown that both high and low temperatures impact the onset of asthma. ${ }^{20-23} 51$ Lam et al suggested that the incidence of asthma increases when the maximum temperature is between $27^{\circ} \mathrm{C}$ and $30^{\circ} \mathrm{C}^{21}$ Currently, there is no consensus on the overall relationship between environmental factors and asthma. Each factor may be subdivided if we are to understand the details of the relationship between these factors and asthma. 
We found that $\mathrm{CO}$ had the greatest impact on asthma. Ho et al suggested that $\mathrm{CO}$ is significantly related to asthma ${ }^{14}$ which is similar to our results. In our air pollutant exposure assessment, we found that $\mathrm{CO}$ had a notable effect on asthma hospitalisation from lag0 to lag5 in Hechi. The statistically significant effects of $\mathrm{CO}$ were also found on lag2- lag4 in Baise. Combining the results of Spearman, we found that the asthma hospitalisation rate associated with $\mathrm{CO}$ was significantly greater than that of $\mathrm{NO}_{2}, \mathrm{SO}_{2}$ and $\mathrm{PM}_{2.5}$ in Guangxi.

In this study, we introduced daily range of temperature as a risk factor, which proved to be positively correlated with asthma in several regions. Dividing factors into several intervals may help in quantifying each risk factor's impact on asthma, and which points to the future work that needs to be done. Findings in our study also provided evidence of air pollutants, which implied that reducing residents from exposing to high concentrations of air pollution may reduce risk of asthma. Limitations of this study should be acknowledged. First, due to lack of data, we did not consider biological air pollutants in our study; dust mites and pollen may both induce severe asthmatic responses. Second, this study did not take into account the effects of indoor pollution and economic factors on asthma.

\section{CONCLUSIONS}

The findings for this study have enhanced our understanding of the spatial heterogeneity of asthma in terms of environmental factors. First, increased CO concentrations exacerbate asthma. Second, correlations between environmental factors differ significantly between regions, indicating that regulatory measures, should also differ between regions. Third, our results suggest that, to improve future studies, risk factors should be divided into intervals.

Contributors YK and RM determined the core idea of the research and edited the article; RM drafted the manuscript; LL and MC offered the daily asthma data and funding; SZ and HS contributed to the development of research objectives and revised the final version of the manuscript; $\mathrm{YH}$ processed the asthma data and validated the data extraction form and GZ contributed to the elaboration of keywords and edited the article.

Funding This paper was supported by the Major Application Project of Guangdong Science and Technology Department (2015B010131016).

Map disclaimer The depiction of boundaries on the map(s) in this article does not imply the expression of any opinion whatsoever on the part of BMJ (or any member of its group) concerning the legal status of any country, territory, jurisdiction or area or of its authorities. The map(s) are provided without any warranty of any kind, either express or implied.

Competing interests None declared.

Patient consent for publication Not required.

Ethics approval This study was approved by the biomedical research ethical subcommittee of Henan University (China).

Provenance and peer review Not commissioned; externally peer reviewed.

Data availability statement Data are available in a public, open access repository. Data are available upon reasonable request. The daily data for air pollution are available on https://www.aqistudy.cn/historydata. The daily data for meteorology are retrieved from National Meteorological Information Center on http://data.cma. $\mathrm{cn} /$. The demographic data mainly came from Guangxi Statistical Yearbook (http:// www.gxtj.gov.cn/). The Sixth National Census came from CNKI (http://data.cnki. net). The asthma-related data used in the present study are partially public, which are available from the corresponding author on reasonable request.

Open access This is an open access article distributed in accordance with the Creative Commons Attribution Non Commercial (CC BY-NC 4.0) license, which permits others to distribute, remix, adapt, build upon this work non-commercially, and license their derivative works on different terms, provided the original work is properly cited, appropriate credit is given, any changes made indicated, and the use is non-commercial. See: http://creativecommons.org/licenses/by-nc/4.0/.

ORCID iD

Yunfeng Kong http://orcid.org/0000-0002-0777-3116

\section{REFERENCES}

1 Busse WW. Expert panel report 3 (epr-3): guidelines for the diagnosis and management of asthma-summary report 2007. J Allergy Clin Immun 2007;120:94-138.

2 Masoli M, Fabian D, Holt S, et al. The global burden of asthma: executive summary of the GINA dissemination committee report. Allergy 2004;59:469-78.

3 To T, Stanojevic S, Moores G, et al. Global asthma prevalence in adults: findings from the cross-sectional World health survey. BMC Public Health 2012;12:204.

4 Bateman ED, Hurd SS, Barnes PJ, et al. Global strategy for asthma management and prevention: GINA executive summary. Eur Respir $J$ 2008;31:143-78.

5 Su N, Lin J, Liu G, et al. [An epidemiological survey of current asthma control status in China]. Zhonghua Nei Ke Za Zhi 2014;53:601-6.

6 Malo JL, Chan-Yeung M, Provencher S. Occupational asthma. J Allergy Clin Immunol 2001;108:317-28.

7 Cook DG, Strachan DP, Carey IM. Health effects of passive smoking. Thorax 1999;54:469.

8 Cai XL. The study of asthma candidate genes IL-4,IL-13,IL-4R and IL1R1 polymorphisms in Guangxi Black-clothes Zhuang children. Master, YouJiang Medical University For Nationalities, Baise, China, 2017.

9 Tian Y, Xiang X, Juan J, et al. Fine particulate air pollution and hospital visits for asthma in Beijing, China. Environ Pollut 2017;230:227-33.

10 Veremchuk LV, Yankova VI, Vitkina TI, et al. Urban air pollution, climate and its impact on asthma morbidity. Asian Pac J Trop Biomed 2016;6:76-9.

11 Zhai WH. The relationship between climatic parameters and air pollutants on emergency room visits for asthma. doctor, medical school of Chinese. Beijing, China: PLA, 2014.

12 Hebbern C, Cakmak S. Synoptic weather types and aeroallergens modify the effect of air pollution on hospitalisations for asthma hospitalisations in Canadian cities. Environ Pollut 2015;204:9-16.

13 Vanos JK, Hebbern C, Cakmak S. Risk assessment for cardiovascular and respiratory mortality due to air pollution and synoptic meteorology in 10 Canadian cities. Environ Pollut 2014; 185:322-32.

14 Ho W-C, Hartley WR, Myers L, et al. Air pollution, weather, and associated risk factors related to asthma prevalence and attack rate. Environ Res 2007;104:402-9.

15 Zhou L, Quanyuan WU, Cai D, et al. Typical air pollutants space-time effects on asthma in jinan City. J Environ Hyg 2015;2015:211-4.

16 Zhang Y, Shao Y, Wang SG, et al. Relationship between air pollutant and respiratory diseases hospital outpatient visits in Beijing. China Environ Sci 2014;34:2401-7.

17 Yan T, Yang DR, Lan L, et al. Relationship between air pollutant and respiratory diseases hospitalization in lanzhou. China Environ Sci 2013;33:175-80.

18 Cai J, Zhao A, Zhao J, et al. Acute effects of air pollution on asthma hospitalization in Shanghai, China. Environ Pollut 2014;191:139-44.

19 Correia Junior MAdeV, Sarinho ESC, Rizzo JA, et al. Lower prevalence and greater severity of asthma in hot and dry climate. $J$ Pediatr 2017;93:148-55.

$20 \mathrm{Li} \mathrm{K}$, Ni H, Yang Z, et al. Effects of temperature variation between neighbouring days on daily hospital visits for childhood asthma: a time-series analysis. Public Health 2016;136:133-40.

21 Lam HC-Y, Li AM, Chan EY-Y, et al. The short-term association between asthma hospitalisations, ambient temperature, other Meteorological factors and air pollutants in Hong Kong: a time-series study. Thorax 2016;71:1097-109. 
22 Xu Z, Huang C, Hu W, et al. Extreme temperatures and emergency department admissions for childhood asthma in Brisbane, Australia. Occup Environ Med 2013;70:730-5.

23 Son J-Y, Bell ML, Lee J-T. The impact of heat, cold, and heat waves on hospital admissions in eight cities in Korea. Int J Biometeorol 2014;58:1893-903.

24 Sousa SIV, Pires JCM, Martins EM, et al. Short-term effects of air pollution on respiratory morbidity at Rio de Janeiro-part II: health assessment. Environ Int 2012;43:1-5.

25 Zhang S, Li G, Tian L, et al. Short-term exposure to air pollution and morbidity of COPD and asthma in East Asian area: a systematic review and meta-analysis. Environ Res 2016;148:15-23.

26 Mireku N, Wang Y, Ager J, et al. Changes in weather and the effects on pediatric asthma exacerbations. Ann Allergy Asthma Immunol 2009;103:220-4.

27 Follenweider LM, Lambertino A. Epidemiology of asthma in the United States. Nurs Clin North Am 2013;48:1-10.

28 Chan EYY, Goggins WB, Yue JSK, et al. Hospital admissions as a function of temperature, other weather phenomena and pollution levels in an urban setting in China. Bull World Health Organ 2013;91:576-84.

29 Pollock J, Shi L, Gimbel RW. Outdoor environment and pediatric asthma: an update on the evidence from North America. Canadian respiratory Journal of the Canadian. Thorac Soc 2017;3:8921917.

30 Kuo C-Y, Pan R-H, Chan C-K, et al. Application of a Time-Stratified case-crossover design to explore the effects of air pollution and season on childhood asthma hospitalization in cities of differing urban patterns: big data analytics of government open data. Int $J$ Environ Res Public Health 2018;15:647.

31 Chang TS, Gangnon RE, David Page C, et al. Sparse modeling of spatial environmental variables associated with asthma. J Biomed Inform 2015;53:320-9.

32 Zhang Y, Ni H, Bai L, et al. The short-term association between air pollution and childhood asthma hospital admissions in urban areas of Hefei City in China: a time-series study. Environ Res 2019;169:510-6.

33 Sha L, Shao M, Liu C, et al. [The prevalence of asthma in children: a comparison between the year of 2010 and 2000 in urban China]. Zhonghua Jie He He Hu Xi Za Zhi 2015;38:664-8.

34 Hua MA, Wang Y, Wang L, et al. Vegetation cover and climate change and rural economic development in relations during last 20 years in karst region of Guangxi, China. Mt Res 2014;32:38-45.

35 Zhang XB, Wang LH, Guo LP, et al. Analysis of the effect of topographical conditions on the artemisinin content in sweet wormwood herb in guangxi,china. Acta Ecol Sin 2009;29:688-97.
36 Guangxi statistical bureau, 2016. Available: http://tjj.gxzf.gov.cn/tjsj/ tjij/2016/indexch.htm

37 The sixth national population census. Available: http://www.stats. gov.cn/tjsj/

38 Hastie T, Tibshirani R. Generalized additive models. Ch Hall 1990;1:587-602.

39 Zhang ZY. Spatiotemporal distributions of PM2.5 using ground monitor data and its relationship with Hospital visiting of respiratory diseases. doctor. Hangzhou, China: Zhejiang University, 2016.

$40 \mathrm{Kim} \mathrm{L}$. Gam: the predictive modeling silver bullet, 2015. Available: https://multithreaded.stitchfix.com/blog/2015/07/30/gam/

41 Dong J, Mengru LI, Sun R, et al. Study on the air quality Standards of China and comparative with foreign standards. Environ Sust Dev 2015;40:87-92.

42 Fan J, Li S, Fan C, et al. The impact of PM2.5 on asthma emergency department visits: a systematic review and meta-analysis. Environ Sci Pollut Res 2015.

43 Ghorani-Azam A, Riahi-Zanjani B, Balali-Mood M. Effects of air pollution on human health and practical measures for prevention in Iran. J Res Med Sci 2016;21:65.

44 Zeng $\mathrm{L}$. The allergic asthma mechanism of Der $f 31$, which is a new allergen of Dermatophagoides farina. Master, Shenzhen university, Shenzhen, China, 2017.

45 YN F, Wang J, Xiang L. Distributions and clinical significance of house dust mite allergens in household dust from house dust miteallergic asthmatic children. Biomed Eng Clin Med 2012;16:586-91.

46 Jacquemin B, Kauffmann F, Pin I, et al. Air pollution and asthma control in the epidemiological study on the genetics and environment of asthma. J Epidemiol Community Health 2012;66:796-802.

47 Ko FWS, Tam W, Wong TW, et al. Temporal relationship between air pollutants and hospital admissions for chronic obstructive pulmonary disease in Hong Kong. Thorax 2007;62:780-5.

48 Seo S, Kim D, Min S, et al. Gis-based association between PM10 and allergic diseases in Seoul: implications for health and environmental policy. Allergy Asthma Immunol Res 2016;8:32-40.

49 Kim D, Seo S, Min S, et al. A closer look at the bivariate association between ambient air pollution and allergic diseases: the role of spatial analysis. Int J Environ Res Public Health 2018;15:1625.

50 Martínez-Rivera C, Garcia-Olivé I, Stojanovic Z, et al. Asociación entre La contaminación ambiental Y Las agudizaciones de asma bronquial en Badalona (Barcelona), 2008-2016. Med Clin 2019;152:333-8.

$51 \mathrm{Xu}$ Z, Crooks JL, Davies JM, et al. The association between ambient temperature and childhood asthma: a systematic review. Int $J$ Biometeorol 2018;62:471-81. 